\title{
TIPAGEM MOLECULAR DE STAPHYLOCOCCUS AUREUS ISOLADOS DE PACIENTES E MEMBROS DA EQUIPE DE ENFERMAGEM*
}

\author{
Ana Cândida Martins Grossi Moreira ${ }^{1}$, Rosiane Ribeiro dos Santos², João Bedendo ${ }^{3}$
}

RESUMO: Estudo quantitativo, exploratório e analítico realizado no período de março a junho de 2010, na Unidade de Terapia Intensiva de um hospital paranaense com o objetivo de identificar o perfil genético das amostras de Staphylococcus aureus isoladas de pacientes e membros da equipe de enfermagem. A suscetibilidade à oxacilina foi avaliada pelo teste de determinação da concentração inibitória mínima e a técnica da reação em cadeia da polimerase foi empregada para a realização da genotipagem. Algumas associações de interesse foram verificadas utilizando teste qui-quadrado, adotando-se $\mathrm{p} \leq 0,05$. Dentre as 61 amostras de 46 pacientes, 44,26\% tiveram grau de similaridade superior a 80\%; seis amostras, pareadas duas a duas, tiveram $100 \%$ de similaridade. Dentre as 20 amostras dos 13 profissionais, $65 \%$ apresentaram similaridade superior a $80 \%$. Observou-se a existência de cepas com perfis genéticos idênticos, ou semelhantes, contudo não é possível afirmar que houve disseminação clonal nesta unidade.

PALAVRAS-CHAVE: Técnicas de tipagem genética; Staphylococcus aureus; Unidades de terapia intensiva; Enfermagem; Resistência à meticilina.

\section{MOLECULAR TYPING OF STAPHYLOCOCCUS AUREUS ISOLATED FROM PATIENTS AND MEMBERS OF THE NURSING TEAM}

ABSTRACT: This quantitative, exploratory and analytical study was undertaken in the period March-June 2010, in the Intensive Care Unit of a hospital in the state of Paraná, with the objective of identifying the genetic profile of samples of Staphylococcus aureus isolated from patients and members of the nursing team. The susceptibility to oxacillin was evaluated by the test for determining the minimum inhibitory concentration, and the polymerase chain reaction technique was used for carrying out the genotyping. Some associations of interest were verified using the Chi-square test, adopting $p=\leq 0.05$. Among the 61 samples from 46 patients, $44.26 \%$ had a degree of similarity over $80 \%$; six samples, paired two-by-two, had $100 \%$ similarity. Among the 20 samples from the 13 health care professionals, $65 \%$ had a similarity of over $80 \%$. The existence of strains with identical, or similar, genetic profiles was observed. However, it was not possible to state that clonal dissemination occurred in this unit. KEYWORDS: Genetic typing techniques; Staphylococcus aureus; Intensive care units; Nursing; Resistance to methycillin.

\section{TIPIFICACIÓN MOLECULAR DE STAPHYLOCOCCUS AUREUS AISLADOS DE PACIENTES Y MIEMBROS DEL EQUIPO DE ENFERMERÍA}

RESUMEN: Estudio cuantitativo, exploratorio y analítico realizado en el periodo de marzo a junio de 2010, en la Unidad de Terapia Intensiva de un hospital de Paraná con el objetivo de identificar el perfil genético de muestras de Staphylococcus aureus aisladas de pacientes y miembros del equipo de Enfermería. La susceptibilidad a la oxacilina fue evaluada por el test de determinación de la concentración inhibitoria mínima y la técnica de reacción en cadena de la polimerasa fue utilizada para realizar el genotipaje. Algunas asociaciones de interés fueron verificadas utilizando test "qui-quadrado", adoptándose $\mathrm{p} \leq 0,05$. De las 61 muestras de 46 pacientes, $44,26 \%$ tuvieron grado de similitud superior a $80 \%$; seis muestras, de parejas dos a dos, tuvieron $100 \%$ de similitud. De las 20 muestras de los 13 profesionales, $65 \%$ presentaron similitud superior a $80 \%$. Se observó la existencia de cepas con perfiles genéticos idénticos, o semejantes, pero no es posible afirmar que hubo diseminación clonal en esta unidad.

PALABRAS CLAVES: Técnicas de tipificación genética; Staphylococcus aureus; Unidades de terapia intensiva; Enfermería; Resistencia a la meticilina.

*Artigo oriundo da dissertação de mestrado intitulada Staphylococcus aureus isolados de pacientes e membros da equipe de enfermagem de uma Unidade de Terapia Intensiva - Programa de Pós-Graduação em Enfermagem da Universidade Estadual de Maringá - UEM, 2011, apoio financeiro da Fundação Araucária.

${ }^{1}$ Enfermeira. Mestre em Enfermagem. Professora do Setor de Enfermagem da Universidade Estadual do Norte do Paraná - UENP CLM. ${ }^{2}$ Enfermeira. Mestranda pelo Programa de Pós-Graduação em Ciências da Saúde da UEM

${ }^{3}$ Enfermeiro. Doutor em Enfermagem. Professor do Departamento de Enfermagem e do Programa de Pós -Graduação em Enfermagem da UEM.

Autor correspondente:

Recebido: $18 / 12 / 2011$

Ana Cândida Martins Grossi Moreira Aprovado: 05/06/2012

Universidade Estadual do Norte do Paraná.

Av. Minas Gerais, 655 - 86300-000 -Cornélio Procópio-PR-Brasil

E-mail: anacandidagrossi@hotmail.com 


\section{INTRODUÇÃO}

Vários microrganismos fazem parte da microbiota normal dos seres humanos ${ }^{(1)}$, entre eles, Staphylococcus aureus (S. aureus), bactérias que habitam a pele e as membranas mucosas, principalmente as fossas nasais ${ }^{(2)}$. Considerando que nos hospitais os principais reservatórios desses agentes são pacientes, funcionários - especialmente os membros da equipe de enfermagem por estar em contato permanente com o paciente - e o próprio ambiente, é importante a identificação de carreadores e da disseminação dessas bactérias por meio da transmissão cruzada ${ }^{(1-3)}$.

$S$. aureus estão relacionados a processos infecciosos em indivíduos internados em Unidade de Terapia Intensiva (UTI), debilitados por imunossupressão, com doenças crônicas, queimaduras, traumas físicos e diversos procedimentos invasivos; podem causar infecções graves, como bacteremia, osteomielite, pneumonia, endocardite, meningite e artrite bacteriana ${ }^{(4-5)}$.

Nas fossas nasais $S$. aureus são encontrados de $20-40 \%$ em indivíduos adultos, sendo que $60 \%$ dos humanos podem ser colonizados temporariamente ${ }^{(6)}$. Aproximadamente $80 \%$ das infecções decorrem da microbiota endógena e são causadas por cepas disseminadas a partir da nasofaringe de carreadores assintomáticos $^{(7)}$. Carreadores nasais persistentes de $S$. aureus têm risco aumentado para o desenvolvimento de infecção, considerando que as características genéticas e raciais do hospedeiro, bem como fatores biológicos do micro-organismo, podem, possivelmente, desempenhar papel importante no processo de colonização ${ }^{(8-9)}$.

S.aureus tem como característica marcante alta versatilidade em adquirir resistência aos antimicrobianos, especialmente às drogas betalactâmicas como a oxacilina ${ }^{(10-11)}$. Esta resistência, em algumas amostras, é mediada por PBP2a, uma proteína fixadora de penicilina (PBP), que tem baixa afinidade por antibióticos $\beta$-lactâmicos. A PBP2a é codificada pelo gene mecA que se situa em um Staphylococcal Chromosomal Cassette mec (SCCmec), o qual confere a resistência à meticilina/oxacilina e cujos genes são transferíveis entre espécies de estafilococos ${ }^{(12)}$.

Técnicas moleculares, entre as quais a Reação em Cadeia da Polimerase (PCR), com a utilização do oligonucleotídeo RW3A ${ }^{(13-14)}$, têm sido empregadas para identificar a presença de genes de resistência e diferenciar isolados com fenótipos idênticos - mesmo perfil de resistência a antimicrobianos, por exemplo identificar rotas de disseminação, relacionar isolados de diferentes fontes e conhecer geneticamente cepas diferentes ou iguais, dispersas no ambiente hospita$1 a r^{(15-16)}$. Cepas geneticamente iguais são definidas como um conjunto de amostras bacterianas geneticamente relacionadas que são indistintas umas das outras por métodos de tipagem molecular, ou amostras tão similares que se presume serem derivadas de um ancestral comum ${ }^{(17)}$.

Tendo em vista o exposto este trabalho teve como objetivo identificar o perfil genético das amostras de $S$. aureus isoladas de pacientes internados em UTI e membros da equipe de enfermagem e comparar os achados com o perfil de suscetibilidade à oxacilina.

\section{MÉTODO}

Trata-se de um estudo quantitativo, exploratório descritivo e analítico realizado no período de março a junho de 2010, em uma UTI da Região Norte do Paraná cujo hospital é centro de referência para a $18^{\mathrm{a}}$ Regional de Saúde. A unidade conta com 10 leitos e aproximadamente 66 internações por mês. Os participantes do estudo foram profissionais da respectiva equipe de enfermagem e pacientes que estiveram internados nesse período, os quais consentiram formalmente em participar da pesquisa. Não houve exclusão entre os membros da equipe de enfermagem, com participação de profissionais de todos os turnos. Em relação aos pacientes, àqueles conscientes foi solicitado consentimento livre e esclarecido e para os impossibilitados de responderem por si, o termo de consentimento foi assinado por familiar responsável, após a leitura e esclarecimentos. O critério inclusão desses foi estar internado há pelo menos 24 horas, sendo excluídos aqueles com traumas no sítio corporal da coleta.

A coleta do material para análise foi obtida através da friç̧ão de swabs esterilizados nos vestíbulos nasais e polpa dos dedos das mãos, totalizando dois swabs por sujeito (um para ambos os vestíbulos nasais e um para as mãos). Os swabs, após a coleta, foram armazenados em estufa a $37^{\circ} \mathrm{C}$ por 24 horas, dispostos em tubos contendo caldo de soja tripticaseína enriquecido com $6,5 \%$ de cloreto de sódio, e neste permaneceu submersa a porção contendo o material coletado ${ }^{(18)}$. Após este período, o caldo foi semeado na superfície de placa de Petri, contendo ágar manitol salgado, que foi incubada em estufa por 24 horas a $37^{\circ} \mathrm{C}$ e, em seguida, deixada por 24 horas em temperatura ambiente ${ }^{(18)}$. As colônias suspeitas de pertencerem a $S$. aureus - colônias opacas, convexas, cremosas e de coloração amarelada - foram 
submetidas ao teste de coloração de Gram, e aquelas identificadas como cocos Gram positivo foram submetidas ao teste de coagulase em tubo ${ }^{(19)}$. As amostras foram consideradas positivas após formação de um coágulo; no teste da coagulase foi utilizada a amostra controle 25923 de $S$. aureus da American Type Culture Collection (ATCC).

A suscetibilidade à oxacilina dos isolados foi determinada pelo método de diluição em ágar; para determinação da Concentração Inibitória Mínima (CIM), a interpretação do teste foi realizada conforme os cortes descritos na tabela $2 \mathrm{C}$ do documento M100-S20 (20).

Os isolados foram submetidos à análise genotípica, que é uma ferramenta importante para a prática clínica, pois fornece dados para o melhor conhecimento da epidemiologia e patogênese dos processos infecciosos. Esta análise foi realizada através da técnica de PCR, com a utilização dos oligonucleotídeos (primers) RW3A (5'TCGCTCAAAACAACGACACC $\left.3^{\prime}\right)^{(15-16)}$. Para a reação com $25 \mu 1$ foram utilizados como reagentes $9,35 \mu 1$ de água Milli Q estéril, 2,5 $\mu 1$ de Tampão 10X, 0,4 $\mu \mathrm{l}$ de Taq polimerase 5U/L, 3,0 $\mu 1$ de dNTP $200 \mu \mathrm{M}, 3,0 \mu \mathrm{l}$ de Cloreto de Magnésio, $2,25 \mu 1$ de DMSO, $1,5 \mu 1$ de primer a $50 \mathrm{pmol}$, e 3,0 $\mu 1$ de DNA. A reação de amplificação foi realizada em termociclador com a seguinte condição: 1 ciclo de $94^{\circ} \mathrm{C}$ por 5 minutos; 40 ciclos de: $93^{\circ} \mathrm{C}$ por 1 minuto, $37^{\circ} \mathrm{C}$ por 1 minuto, $72^{\circ} \mathrm{C}$ por 1 minuto, e no final um ciclo de $72^{\circ} \mathrm{C}$ por 8 minutos. Após o término da reação os tubos foram mantidos a $4^{\circ} \mathrm{C}$ até a corrida eletroforética $^{(15-16)}$.

A eletroforese dos produtos amplificados foi realizada em gel de agarose a 1,5\% corada com brometo de etídio, a 90 volts por 3 horas. Ladder 100 $\mathrm{pb}$ foi utilizado como marcador para a quantificação das bandas ${ }^{(15)}$. A identificação do gene mecA das amostras resistentes à oxacilina também foi realizada por PCR ${ }^{(17)}$. Os primers utilizados foram: MRS1- 5' TAGAAATGACTGAACGTCCG 3' e MRS2- 5'TTGCGATCAATGTTACCGTAG 3'.

Para a reação de amplificação com $25 \mu 1$ foram utilizados os seguintes reagentes em suas respectivas quantidades: $12,1 \mu \mathrm{l}$ de água Milli Q estéril, 2,5 $\mu 1$ de tampão 10X PCR (10 mM Tris $\mathrm{HCl}$ [pH8.8]), 1,5 $\mu 1$ de Cloreto de Magnésio (50 mM), 1,5 $\mu 1$ de dNTP (10 $\mathrm{mM}), 2 \mu 1$ de cada primer $(50 \mathrm{mM}), 0,4 \mu 1$ de Taq polimerase $(5 \mathrm{U} / \mu \mathrm{l})$ e $3,0 \mu \mathrm{l}$ de DNA de cada amostra. A amplificação se deu em termociclador com o seguinte programa: $95^{\circ} \mathrm{C}$ por 10 minutos, 30 ciclos de: $95^{\circ} \mathrm{C}$ por 30 segundos, $52^{\circ} \mathrm{C}$ por 30 segundos, $72^{\circ} \mathrm{C}$ por 1 minuto, e por fim, $72^{\circ} \mathrm{C}$ por 10 minutos. O produto amplificado foi visualizado após eletroforese em gel de agarose a $1,5 \%$ corado com brometo de etídeo. A corrida foi realizada a 100 watts por um período de 60 minutos com posterior visualização e fotografia em luz ultravioleta. O amplicom de cada amostra foi de 154 pares de base (pb), sendo comparado com Ladder $100 \mathrm{bp}$. Como controle positivo foi utilizado a cepa $S$. aureus ATCC 33591 por expressar o gene.

Os dados foram tabulados no programa Microsoft Excel ${ }^{\circledR}$ versão 2003 e descritos a partir de tabelas de contingência. Algumas associações de interesse foram verificadas utilizando teste qui-quadrado, adotando-se nível de significância de $5 \%(\mathrm{p}<0,05)$. Para análise genotípica foi utilizado o programa Bionumerics que proporcionou a confecção do dendograma.

O desenvolvimento do estudo ocorreu em conformidade com o preconizado pelo Conselho Nacional de Pesquisa, sendo aprovado pelo Comitê de Ética e Pesquisa (COPEP) da Universidade Estadual de Maringá sob parecer n. 395/2010.

\section{RESULTADOS}

Participaram do estudo 84 pacientes e 22 profissionais de enfermagem, totalizando 212 amostras coletadas, sendo duas amostras por sujeito. Entre os 84 pacientes participantes do estudo, 46 (54,76\%) apresentaram positividade para S.aureus, sendo que em $15(32,61 \%)$ desses a bactéria foi isolada de vestíbulo nasal, 16 (34,78\%) de mãos e $15(32,61 \%)$ concomitantemente em ambos os sítios corporais. Dos 46 pacientes com resultado positivo para S.aureus obteve-se 61 amostras de material clínico dos sítios corporais anteriormente informados, e cujos isolados tipificados foram avaliadas quanto ao grau de similaridade; 27 (44,26\%) tiveram grau de similaridade superior a $80 \%$ e as demais $34(55,74 \%)$ apresentaram grau de similaridade variando entre 20 e $80 \%$. Entre os isolados tipificados, seis amostras, pareadas duas a duas, tiveram $100 \%$ de similaridade, duas de isolados de mãos e quatro de vestíbulos nasais. Os resultados da análise de similaridade entre as amostras de S.aureus isoladas de pacientes internados em UTI são apresentados na figura 1.

Entre os 22 sujeitos pertencentes à equipe de enfermagem, $13(59,09 \%)$ apresentaram positividade para S.aureus, cinco $(38,46 \%)$ isolados nos vestíbulos nasais, uma $(7,69 \%)$ nas mãos, e $7(53,85 \%)$ concomitantemente em ambos os sítios corporais. Dos 13 
profissionais com resultado positivo obteve-se 20 amostras de material clínico dos sítios corporais anteriormente informados, e cujos isolados tipificados foram avaliados quanto ao grau de similaridade; 13 (65\%) apresentaram similaridade superior a $80 \%$, sendo que dessas quatro $(30,77 \%)$ tiveram similaridade de aproximadamente $90 \%$. As demais, 7 (35\%) apresentaram similaridade inferior a $80 \%$. Os resultados da análise de similaridade entre as amostras de $S$. aureus isolados dos membros da equipe de enfermagem são apresentados na figura 2 .

Comparando-se os resultados da similaridade genética no grupo dos pacientes com o perfil de suscetibilidade observou-se que das seis amostras isoladas, pareadas duas a duas e que tiveram $100 \%$ de similaridade entre si, 83,33\% apresentou resistência à oxacilina, e dessas, em quatro foi identificado o gene mecA. Somente duas, geneticamente idênticas, apresentaram perfis fenotípicos diferentes, sendo uma amostra sensível à oxacilina e a outra resistente; a amostra resistente à oxacilina possuía o gene mecA.

Quando comparadas as amostras procedentes dos dois grupos estudados (Figura 3) verificou-se que 10 $(12,35 \%)$ amostras, pareadas duas a duas, tiveram $100 \%$ de similaridade entre si. A análise do teste de resistência para oxacilina pelo método de determinação da CIM mostrou que 8 destas amostras foram resistentes à oxacilina, sendo que $7(87,5 \%)$ tinham o gene mecA.

Quatro amostras de ambos os grupos, pareadas duas a duas, que se mostraram geneticamente idênticas, apresentaram perfis de resistência diferentes, sendo duas sensíveis à oxacilina e duas resistentes, porém somente uma possuía o gene mecA. Os resultados da comparação entre a proporção de bactérias com perfis genéticos idênticos e não idênticos são mostrados na tabela 1 .

Tabela 1 - Comparação entre as proporções de bactérias com perfil genético idêntico e não idêntico isoladas de pacientes e membros da equipe de enfermagem de uma UTI de um hospital geral da região norte do Paraná, 2011

\begin{tabular}{|c|c|c|c|c|}
\hline Variáveis & $\begin{array}{l}\text { Perfil de res } \\
\text { Oxacilina* } \\
\text { Resistentes }\end{array}$ & $\begin{array}{l}\text { sistência a } \\
\text { Sensíveis }\end{array}$ & Total & $\begin{array}{l}\text { Valor } \\
\mathbf{p}^{* *}\end{array}$ \\
\hline Perfil genético & & & & 0,3814 \\
\hline Idênticas & $08(80 \%)$ & $02(20, \%)$ & 10 & \\
\hline Não idênticas & $47(66,2 \%)$ & $24(33,8 \%)$ & 71 & \\
\hline Total & 55 & 26 & 81 & \\
\hline
\end{tabular}

* Utilizou-se o teste da Concentração Inibitória Mínima.

** Teste Qui-quadrado de Pearson.

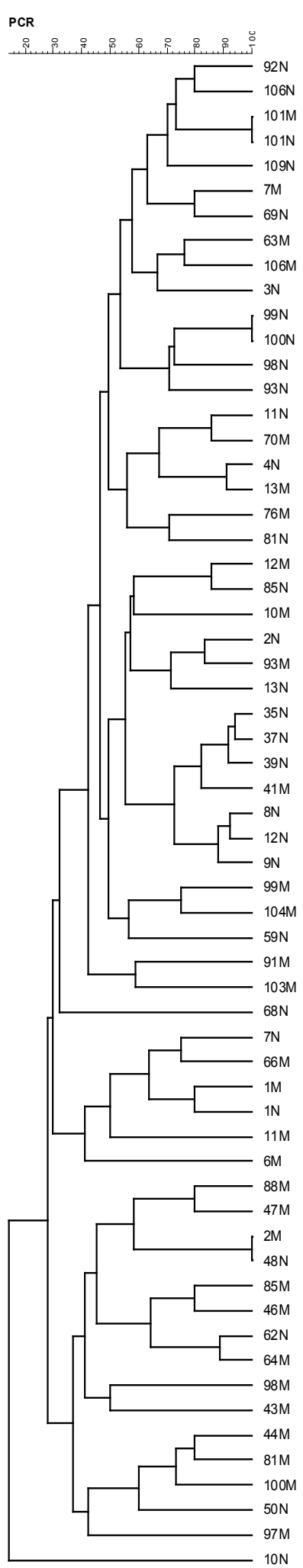

Figura 1 - Análise de similaridade das amostras de S.aureus isolados de pacientes. Maringá, 2010 


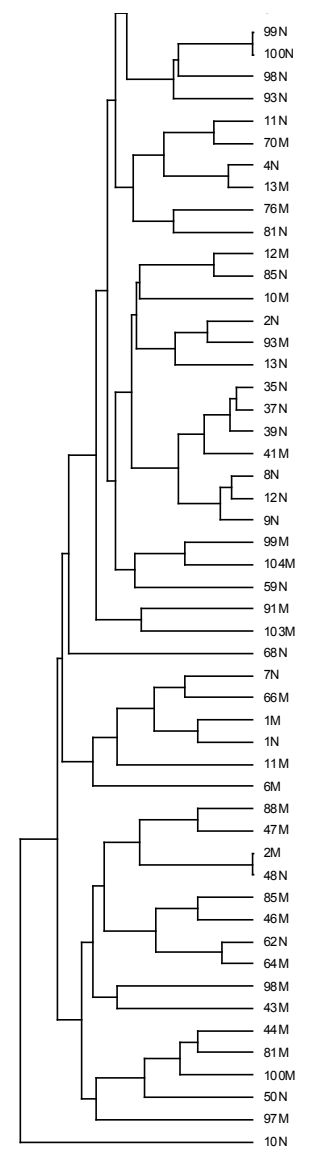

Figura 2 - Análise de similaridade das amostras de S.aureus isolados da equipe de enfermagem. Maringá, 2010

\section{DISCUSSÃO}

Neste estudo a tipagem genética das amostras isoladas de pacientes mostrou que seis amostras, pareadas duas a duas, tiveram $100 \%$ de similaridade; em apenas um obteve-se amostras com genótipos idênticos entre mãos e vestíbulos nasais. Este resultado indica a existência de cepas com perfis genéticos idênticos, ou semelhantes, neste setor, porém não é possível afirmar que haja uma disseminação clonal na UTI.

Para o grupo de amostras isoladas da equipe de enfermagem nenhuma apresentou similaridade de $100 \%$, não havendo relação de similaridade entre mãos e vestíbulos nasais de um mesmo indivíduo. Este perfil heterogêneo não confirmou a presença de um clone disseminado entre os membros da equipe de enfermagem.

Estudos utilizando a técnica de PCR têm mostrado bons resultados para avaliação da similaridade de amostras de $S$. aureus isoladas de diferentes sítios

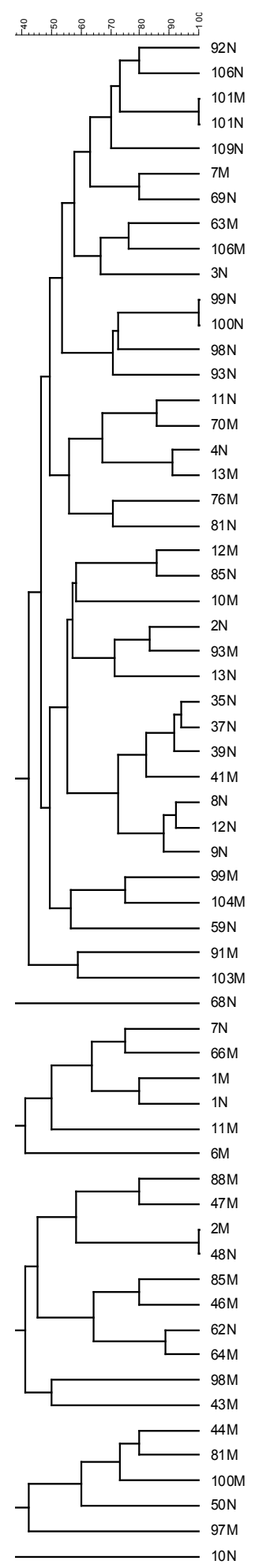

Figura 3 - Análise de similaridade das amostras de S.aureus isoladas dos pacientes e da equipe de enfermagem. Maringá, 2010 
ou fontes ${ }^{(15,17)}$. Alguns autores destacam o importante papel deste método genotípico no delineamento de pesquisa de similaridade de amostras quando o antibiograma não fornece parâmetros suficientes ${ }^{(17)}$. Estudo utilizando a técnica de PCR demonstrou que havia a prevalência de um mesmo clone entre $80,4 \%$ dos isolados de $S$. aureus obtidos em uma UTI, representando uma ampla disseminação clonal ${ }^{(17-18)}$.

O estabelecimento de correlação entre resistência antimicrobiana e disseminação clonal de $S$. aureus é uma ferramenta importante na vigência de surtos ou mesmo em condições de endemicidade. Estudos sobre a colonização nasal por S.aureus com resistência à meticilina e sensibilidade à mupirocina em pacientes de uma UTI Cirúrgica demonstraram, por meio da PCR com o primer RW3A, a existência de clones entre as amostras resistentes à mupirocina. No presente estudo não se observou correlação entre similaridade genética e sensibilidade, ou resistência à oxacilina. Os resultados permitiram conhecer o perfil genético do $S$. aureus carreados pelos pacientes e membros da equipe de enfermagem.

\section{CONSIDERAÇÕES FINAIS}

Os resultados da tipagem genética mostraram um perfil heterogêneo entre as amostras de S.aureus isoladas de pacientes e membros da equipe de enfermagem. Observou-se a existência de cepas com perfis genéticos idênticos, ou semelhantes, dentro do ambiente hospitalar, contudo não é possível afirmar que haja disseminação clonal na UTI desta instituição, em virtude da quantidade de cepas indistintas.

A tipagem genética possibilitou relacionar isolados de diferentes fontes e identificar geneticamente cepas diferentes, ou iguais, dispersas no ambiente hospitalar. Neste estudo as proporções de similaridade clonal e o atributo de suscetibilidade à oxacilina foram independentes, sem diferença estatística.

\section{REFERÊNCIAS}

1. Martins LT. Staphylococcus. In: Trabulsi LR, et al. Microbiologia. $3^{\mathrm{a}}$ ed. São Paulo: Atheneu, 2002. p. 149-156.

2. Ricardo SB. Emergência de S. aureus Meticilinaresistente (MRSA) na comunidade. Prática hospitalar 2004; (34):131-4.

3. Giarola LB, Baratieri T, Costa AM, Bedendo J,
Marcon SS, Waidman MAP. Infecção hospitalar na perspectiva dos profissionais de enfermagem: um estudo bibliográfico. Cogitare enferm. 2012;17(1):151-7.

4. Tortora GJ, Funke BR, Case CL. Bacterias. In: Trabulsi LR, Alterthum F. Microbiologia. $8^{\mathrm{a}}$ ed. Porto Alegre: Artmed, 2005.

5. Teixeira LM, et al. Staphylococcus aureus. In: Trabulsi LR, Alterthum F. Microbiologia. 5a ed. São Paulo: Atheneu; 2008. p. 307-12.

6. Bania J, Dabrowska A, Korzekwa K, Zarczynska A, Bystron J, Chrzanowska J, et al. The profiles of enterotoxin genes in Staphylococcus aureus from nasal carrieres. Lett. appl. microbiol. 2006;42(4):315-20.

7. Wertheim H, Vos M, Ott A, Van Belkum A, Voss A, Kluytmans J, et al. Risk and outcome of nosocomial Staphylococcus aureus bacteraemia in nasal carriers versus noncarriers. Lancet 2004;364(9435):703-5.

8. Ferreira AM, Andrade D, Rigotti MA, Almeida MTG. Methicillin - resistant Staphylococcus aureus on surfaces of an intensive care unit. Acta paul. enferm. 2011; 24(4):453-8

9. Perez LRR, D'azevedo PA. Clonal types and antimicrobial resistance profiles of methicillin-resistant Staphylococcus aureus isolates from hospitals in south Brazil. Rev. Inst. Med. Trop. São Paulo. 2008;50(3):135-7.

10. Naves KSC, Trindade NV, Gontijo FPP. Methicillinresistant Staphylococcus aureus bloodstream infection: risk factors and clinical outcome in non-intensive-care units. Rev. Soc. Bras. Med. Trop. 2012;45(2):189-93.

11. Brasil. Agência Nacional de Vigilância Sanitária. Detecção e identificação de bactérias de importância médica. Módulo V. Brasilia; 2004. [acesso em 10 out 2011]. Disponível: http://anvisa.gov.br/servicosaude/ manuais/microbiologia/mod_5_2004.pdf

12. Deurenberg RH, Stobberingh EE. The evolution of Staphylococcus aureus. Infec. genet. evol. 2008;8(6):747-63.

13. Del Vecchio VG, Petroziello JM, Gress MJ, McCleskey FK, Melcher GP, Crouch HK, et al. Molecular genotyping of methicillin-resistant Staphylococcus aureus via fluorophore enhanced repetitive-sequence PCR. J. clin. microbiol. 1995;33(8):2141-4.

14. Reinoso E, Bettera S, Odierno L, Bogni C. Rep-PCR of Staphylococcus aureus strains isolated from bovine mastitis in Argentina. Braz. J. Vet. Res. Anim. Sci. 2007; 4(Supl.):115-21.

Cogitare Enferm. 2012 Jul/Set; 17(3):437-43 
15. Liao RS, Storch GA, Buller RS, Orscheln RC, Mardis ER, Armstrong JR, et al. Blinded comparison of repetitivesequence PCR and multilocus sequence typing for genotyping methicillin-resistant Staphylococcus aureus isolates from a Children's Hospital in St. Louis, Missouri. J. clin. microbiol. 2006;44(6):2254-7.

16. Sommerauser J, Kloppert B, Wolter W, Zschock M, Sobiraj A, Failing K, et al. The epidemiology of Staphylococcus aureus infections from subclinical mastitis in dairy cows during a control programme. Vet. microbiol. 2003;96(1):91-102.

17. Siripommongcolchain T, Chomvarin C, Chaicumpar $\mathrm{K}$, Limpaiboon T, Wongkhun C. Evolution of different primers for detecting mecA genes by PCR in comparison with phenotypic methods for discrimination of meticillinresistant Staphylococcus aureus. Southeast Asian J. Trop. Med. Public. Health. 2002;33(4):758-63.

18. Dias Filho BP, Abreu Filho BA, Cardoso CL, Nakamura CV, Garcia LB, Guilhermetti M, Tognin MCB, et al. Manual de aulas práticas: Enfermagem. Maringá: Universidade Estadual de Maringá. Departamento de Análises Clínicas, 2001.

19. Koneman EW, Allen SD, Janda WM, Schreckenberger PC, Win WC. Diagnóstico microbiológico: texto e atlas colorido. $5^{\text {a }}$ ed. Rio de Janeiro: Medsi, 2001. p. 551- 88.

20. Clinical and Laboratory Standards Institute. Performance Standards for antimicrobial disk susceptibility testes: approved stardard. $10^{\mathrm{a}}$ ed. Waine: Clinical and Laboratory Standards Intitute, 2009. 